\title{
The "Difficult" Colorectal Polyps and Adenomas: Practical Aspects
}

\author{
László Herszényi \\ Department of Gastroenterology, Medical Centre Hungarian Defence Forces, Semmelweis University Teaching \\ Hospital, Budapest, Hungary
}

\section{Keywords}

Adenoma · Polyp · Colonoscopy · Polypectomy · Technique

\begin{abstract}
Background: Colonoscopy is the gold standard for adenoma detection. All endoscopists who perform colonoscopy must by mandate be skilled to perform polypectomy. However, there are significant differences between endoscopists in terms of the polyp detection rate and in the effectiveness of polypectomy. Summary: Most polyps identified can be managed by conventional polypectomy and do not pose a significant challenge for resection to an adequately skilled and trained endoscopist. Up to $15 \%$ of polyps may be considered "difficult", unsuitable for conventional endoscopic removal because of size, morphology, site, or access grade. Endoscopist-, patient- and polyp-specific viewpoints influence the management of difficult polyps. Advances in endoscopic resection techniques have led to extended indications for polypectomy. Conventional endoscopic removal of colorectal polyps is associated with a small but not negligible incidence of complications, most commonly bleeding and perforation. Advanced techniques for difficult polyps can potentially cause significant, even life-threatening complications. In addition, in the presence of "difficult" polyps,
\end{abstract}

complications are more common. Key Messages: Multiple techniques are now available for the resection of difficult polyps. The endoscopist should individualize the appropriate approach for the treatment of difficult polyp in order to maximize oncological safety, efficacy and minimize complications and unnecessary surgery.

(c) 2018 S. Karger AG, Basel

\section{Introduction}

Colonoscopy is the gold standard for polyp detection. It has been clearly established that professionally performed endoscopic polypectomy reduces the incidence of colorectal cancer and mortality by decreasing the subsequent development of colorectal cancer $[1,2]$. The outcome quality and the degree of safety provided by colonoscopy are mainly influenced by the technical skill and experience of the endoscopist in identifying and removing polyps. It has been shown that there is important difference between endoscopists for detection rates of conventional and sessile serrated polyps $[3,4]$.

The vast majority of polyps identified are small, can be managed by conventional polypectomy and do not cause a significant challenge for resection to an adequately

\section{KARGER}

(c) 2018 S. Karger AG, Basel

E-Mail karger@karger.com

www.karger.com/ddi
László Herszényi, MD, PhD, DSc, MSc

Department of Gastroenterology, Medical Centre Hungarian Defence Forces Semmelweis University Teaching Hospital

Podmaniczky str. 111, HU-1062 Budapest (Hungary)

E-Mail herszenyi.laszlo@gmail.com 
skilled and trained endoscopist. However, up to $15 \%$ of colorectal polyps may be considered "difficult" and unsuitable for conventional endoscopic removal because of size, morphology, site, or access grade.

\section{"Difficult" Colon Polyp: Definition}

In the everyday practice, the definition of a "difficult" colon polyp is not well established. A "difficult" colon polyp can be defined as any polyp that is difficult to remove for an average endoscopist. A "difficult" colorectal polyp may be characterized by the size, morphology, location, number and the difficult assessment of the grade of malignancy before removal [5-8]. The main characterization of the "difficult" colorectal polyp is summarised by Table 1 .

Usually many "difficult" colorectal polyps can be removed by an advanced endoscopist. In clinical practice, any polyp referred to a more experienced endoscopist following an index colonoscopy may be considered "difficult". In more objective way, polyps that are larger than $1.5-2 \mathrm{~cm}$ are flat or laterally spreading, located in right colon or cecum, located around haustral folds and are difficult to access should always be considered "difficult". The endoscopic removal of large pedunculated polyps with large and thick stalk in the left colon or sigmoid are associated with increased risk of bleeding because from large vessels within the pedicle. Therefore, these polyps should also be considered "difficult" $[9,10]$. Polypectomy of a giant pedunculated colorectal polyp (greater than $3 \mathrm{~cm}$ ) is also technically demanding because of the relative risk of invasive cancer and post-polypectomy bleeding, and therefore, each case should be individually evaluated in a specialist unit for feasibility of endoscopic resection $[11,12]$. An important study focusing on polyp-specific risk factors (English Bowel Cancer Screening Programme) has confirmed that the greatest risk factor for both post-polypectomy bleeding and perforation is polyp size [13]. Further, the number of polyps also satisfies the concept of "difficult" as the incidence of complications and recurrence correlates with the number of advanced colorectal adenomas [14].

\section{Management of "Difficult" Colorectal Polyps}

\section{General Considerations}

During earlier times, the management of a "difficult" colorectal polyp several aspects had to be taken into ac-
Table 1. The main characterization of the difficult colorectal polyp*

Size

Large $(>1.5-2 \mathrm{~cm})$

Giant polyp $(>3 \mathrm{~cm})$

Big head

Large pedunculated polyps with thick or short stalk

Morphology

Flat or flat depressed

Sessile

Laterally spreading

Irregular surface

Irregular pit pattern

Villous or granular

Location

Right colon and cecum

Appendix orifice

Ileocecal valve

Located behind folds

Number

Multiple (>3)

Difficult assessment of the grade of malignancy before removal

* According to references [5-8].

Table 2. General considerations before management of "difficult" colorectal polyps*

- Patient age and significant comorbidities

- Polyp size, number, morphology location

- Natural history of polyps

- Malignant potential of any discovered polyp

- Index histology, presence or absence of high grade dysplasia

- Macroscopic features of malignancy: ulceration, induration,

friability, fixity, non-lifting sign

- Adequately skilled and trained endoscopist

* According to reference [8].

count (Table 2). In particular, in patients with advanced age, the natural history of polyps (slow growth and slow malignant transformation) and significant comorbidities should determine the therapeutic approach. During colonoscopy, the malignant potential of any discovered colorectal polyp should be also evaluated. Induration, ulceration, friability, fixity, and non-lifting sign are the major endoscopic, macroscopic features of malignancy, while polyp size, villous histology and high-grade dysplasia on initial biopsy are strong histologic predictors of malignancy [8]. 


\section{Endoscopic Resection}

Many different endoscopic resection techniques are available. Polypectomy techniques have continued to develop over time. Advances in endoscopic resection have led to expanded indications for endoscopic polypectomy. The indication for the different techniques is mainly based on the size, morphology of the lesion and on the risk of submucosal invasion. Based mainly on the European Society of Gastrointestinal Endoscopy (ESGE) consensus guideline, nowadays we have a better understanding of how to perform safe and effective polypectomy [15-17]. Because most "difficult" polyps are benign, endoscopic treatment should be preferred whenever possible rather than surgery. However, endoscopic polyp resection should be done by following a standardized approach. It has been suggested that the main steps leading to a successful polypectomy are the following: accurately locate the polyp, determine the number of polyps and size of polyps, analyse the polyp's shape and surface, position the polyp before resection, estimate polyp resectability and asses the skill of the endoscopist. Moreover, all essential equipment and accessories necessary for successful polypectomy should be available [5-8]. In clinical practice, most polyps identified at colonoscopy are small and not malignant, and therefore, are amenable to almost all endoscopists to conventional polypectomy. However, the management of complex and "difficult" colorectal polyps varies in practice. In the presence of a "difficult" polyp, usually a repeated colonoscopy by an experienced endoscopist in sophisticated polypectomy is suggested. Further, collaboration with specialists in complex polypectomy may be essential in determining the appropriate management of "difficult" polyps [18, 19].

\section{Conventional Polypectomy}

Diminutive polyps (1-5 $\mathrm{mm}$ in size) represent the majority of colorectal polyps. Approximately $80 \%$ of all polyps recognized during colonoscopy are considered diminutive $[17,20]$. As diminutive colorectal polyps are at low risk for malignancy, different strategies have been proposed. The "diagnose and leave behind" strategy means that if diminutive polyps are located in the rectosigmoid, resection is not always mandatory when the lesion is predicted with high confidence to be hyperplastic. For all other diminutive polyps, endoscopic polypectomy and histopathological examination are suggested. The "resect and discard" strategy is a matter of discussion. This strategy is recommended only for expert centres [16]. The ESGE guideline recommends cold snare polypectomy (CSP) as the preferred technique for removal of diminutive polyps (size $\leq 5 \mathrm{~mm}$ ) because it has been reported to be superior to cold biopsy forceps in terms of complete resection. CSP has low complication rates and adequate tissue sampling for histology [15]. Although strong evidence comparing efficacy with hot snare polypectomy is lacking, ESGE suggests CSP for sessile polyps in size 6-9 $\mathrm{mm}$ because of its better safety profile [15].

Conventional snare polypectomy for "difficult" polyps has been demonstrated to be feasible, effective and safe. Studies on patients with "difficult" polyps referred directly to the colorectal surgeons for resection have demonstrated that during repeated colonoscopy, effective snare polypectomy was possible in $32-74 \%$ of cases [8]. The ESGE guideline recommends hot snare polypectomy for pedunculated polyps. For prevention of bleeding in "difficult" pedunculated polyps (with head $\geq 2 \mathrm{~cm}$ or a stalk $\geq 1.5 \mathrm{~cm}$ ), injection of dilute adrenaline and/or mechanical hemostasis is recommended [15]. It has been shown that the use of endoloops or endoclips (mechanical prophylaxis) can be superior to adrenaline injection and combination of mechanical prophylaxis with adrenalin injection significantly decreased post polypectomy bleeding in comparison with injection alone [21-23]. ESGE recommends that large $(\geq 2 \mathrm{~cm})$, sessile and laterally spreading "difficult" polyps should be always treated and removed by trained and experienced endoscopist in appropriately resourced tertiary endoscopic centre. Effective risk stratification of "difficult" polyps can provide important information on the polyp complexity and complication rates of endoscopic resection. This strategy can be effectively used not only for service planning but also providing prognostic information for patients $[15$, 24-26].

Advanced endoscopic resection techniques should be considered for "difficult", complex polyps that are not amenable to conventional snare polypectomy. In cases of suspected superficial invasive carcinoma, "en bloc" resection techniques such as endoscopic mucosal resection (EMR), endoscopic submucosal dissection (ESD) or surgery are indicated. The main criteria of effective and curative endoscopic treatment are the following: en bloc R0 resection, well differentiated adenocarcinoma, $<1 \mathrm{~mm}$ submucosal invasion and absence of lymphovascular invasion $[15,27]$.

\section{Endoscopic Mucosal Resection}

EMR, first developed in Japan, is an endoscopic technique that refers to the removal of a mucosal lesion confined to the superficial layers. In toto resection rates are higher for pedunculated polyps than that for sessile of flat 
lesions. EMR is a technique where fluid is injected into the submucosal space, creating a submucosal layer between the muscularis propria and submucosal space. EMR is typically used for the removal of lesions smaller than $2 \mathrm{~cm}$ or piecemeal removal of larger lesions. For large lesions, incomplete resection is common, which can lead to local recurrence. Therefore, when performing EMR, en bloc resection is preferred to "piecemeal" polypectomy. En bloc resection provides more exact histologic evaluation and is associated with lower recurrence rates. Piecemeal polypectomy is recommended for the resection of sessile or flat polyps larger than $2 \mathrm{~cm}$. During piecemeal polypectomy, it is suggested that the resection be started at the proximal part of the polyp and then finished distally [6, 28-30]. In a meta-analysis, Belderbos et al. [31] included 33 studies and concluded that the overall recurrence for EMR was 15\%, while local recurrence rate was $3 \%$ for en bloc resection and $20 \%$ for piecemeal resection. According to a more recent meta-analysis including 50 studies with 6,442 patients and 6,779 "difficult" polyps, the endoscopic cure rate for these large and complex polyps measuring $>2 \mathrm{~cm}$ was as high as $96 \%$. Endoscopic perforation occured in $1.5 \%$, bleeding in $6.5 \%$, and the rate of progression to surgery was only $8 \%$ [32]. Despite these positive outcomes, piecemeal polypectomy has important limitations. A piecemeal specimen can limit adequate pathological examination and this may lead to the inability to identify focal submucosal invasion; therefore, piecemeal EMR does not allow completeness of resection unlike en bloc resection. Accordingly, the risk of lymph node metastases could be underestimated, resulting in non-curative therapy without recommending definitive surgical resection. Based on these, according to the ESGE definition, a successful EMR should be defined endoscopically only if there is an absence of neoplastic tissue at the completion of the procedure after careful inspection of the post-EMR mucosal defect and margin. Table 3 summarizes the main benefits and limitations of EMR. Due to deficiencies of EMR, ESGE recommends that after EMR surveillance, colonoscopy by advanced imaging and systematic biopsy is mandatory [15].

\section{Endoscopic Submucosal Dissection}

ESD was initially described in 1988 for the resection of gastric lesions and later adopted for "difficult" colorectal polyps [33]. ESD can be considered for colorectal lesions that otherwise cannot be optimally and radically removed by snare-based techniques, particularly if the lesions are larger than $2 \mathrm{~cm}$. ESD enables en bloc (in toto) resection of large superficial colorectal polyps regardless of their
Table 3. The main benefits and limitations of EMR and ESD

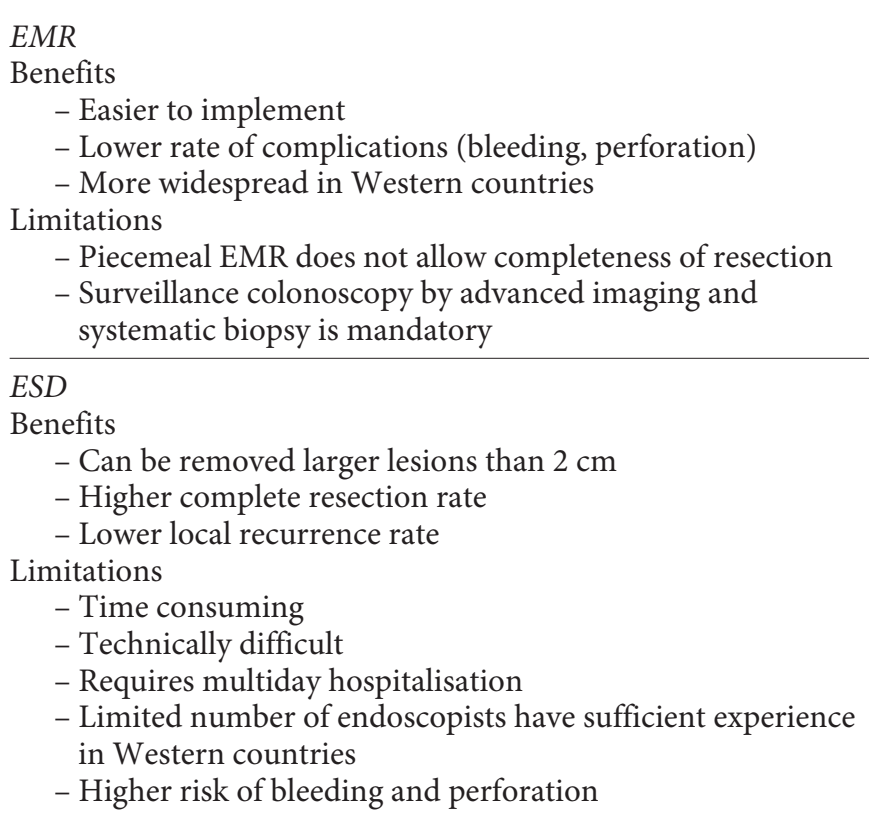

EMR, endoscopic mucosal resection; ESD, endoscopic submucosal dissection.

size and location $[34,35]$. The complete resection rates in Japan reach 95\%, whereas in Europe they are not more than $70-80 \%$. ESD has a higher en bloc resection rate and local recurrence rate in comparison with $\operatorname{EMR}[36,37]$. However, ESD is time consuming, technically difficult, often requires post-procedural multiday hospitalisation, and in Western countries, a limited number of endoscopists have sufficient experience with this procedure. In addition, ESD is associated with a higher risk of bleeding (10-20\%) and perforation (5-10\%; Table 3) [38-40].

\section{Surgery}

Surgery, particularly laparoscopic colorectal resection is currently a widely accepted treatment for "difficult" and complex polyps not amenable to endoscopic removal. According to ESGE recommendation, polyps with characteristics of deep submucosal invasion (proven by advanced endoscopic imaging techniques) should be referred for surgery [15]. Laparoscopic resection is a real alternative to ESD or EMR with high risk. In most cases, local lymph node metastasis can also be removed during laparoscopic surgery. However, laparoscopic resection is associated with complication rates of over $15 \%$. Conversion to open surgery is necessary in less than $5 \%$. Therefore, the benefit and risk of laparoscopic surgery should be always taken 
into account. The potential risks of laparoscopic resection may outweigh the potential risk of lymph node metastasis if the "difficult" polyps are not resected en bloc. Until now, no important study showed that ESD has better results and outcomes in comparison with surgery [41-45]. For "difficult", endoscopically unresectable rectal polyps, transanal excision is the method of choice. It has been shown that transanal endoscopic microsurgery and transanal minimally invasive surgery are effective techniques for the surgical removal of these polyps $[46,47]$.

\section{Combined Methods: Future Directions}

Combined endoscopic-laparoscopic surgery is a novel resection technique aimed to resect "difficult" polyps while preserving the colon without a formal resection. Two techniques have been described. Laparoscopic-assisted colonoscopic polypectomy involves external manipulation of the polyp for adequate orientation. The colonoscopic-assisted laparoscopic resection involves endoscopic localisation of the polyp margins. Feasible pre- liminary data are promising: $70-87 \%$ of polyps not amenable to routine snare polypectomy can be successfully removed with these techniques $[8,35,48]$.

Endoscopic full thickness resection (EFTR) is another novel treatment of "difficult" and complex polyps not amenable to conventional endoscopic resection [49]. In a recent study, EFTR was technically successful in $89.5 \%$ in patients with difficult adenomas and benign histology, R0 resection rate was $77 \%$, with adverse event of $10 \%$, including $2 \%$ rate of emergency surgery [50]. Data comparing the effectiveness and safety of combined endoscopic-laparoscopic surgery and EFTR with ESD or surgery is lacking; therefore, further comparative studies are needed to evaluate the real clinical impact and long-term outcome of these new combined techniques in the treatment of "difficult" polyps.

\section{Disclosure Statement}

The author declares that there are no conflicts of interest to disclose.

\section{References}

1 Zauber AG, Winawer SJ, O’Brien MJ, Lansdorp-Vogelaar I, van Ballegooijen M, Hankey $\mathrm{BF}$, et al: Colonoscopic polypectomy and long-term prevention of colorectal-cancer deaths. N Engl J Med 2012;366:687-696.

2 Wittmann T, Stockbrugger R, Herszényi L, Jonkers D, Molnár B, Saurin JC, et al: New European initiatives in colorectal cancer screening: Budapest declaration. Official appeal during the Hungarian presidency of the council of the European union under the auspices of the United European gastroenterology federation, the European association for gastroenterology and endoscopy and the Hungarian society of gastroenterology. Dig Dis 2012;30:320-322.

3 Adler A, Wegscheider K, Lieberman D, Aminalai A, Aschenbeck J, Drossel R, et al: Factors determining the quality of screening colonoscopy: a prospective study on adenoma detection rates, from 12,134 examinations (Berlin colonoscopy project 3, BECOP-3). Gut 2013;62:236-241.

4 Fan C, Younis A, Bookhout CE, Crockett SD: Management of serrated polyps of the colon. Curr Treat Options Gastroenterol 2018;16: 182-202.

5 Mönkemüller K, Neumann H, Fry LC, Ivekovic H, Malfertheiner P: Polypectomy techniques for difficult colon polyps. Dig Dis 2008; $26: 342-346$.

6 Vormbrock K, Mönkemüller K: Difficult colon polypectomy. World J Gastrointest Endosc 2012;4:269-280.
7 Jung M: The "difficult" polyp: pitfalls for endoscopic removal. Dig Dis 2012;30(suppl 2): 74-80.

8 Pidala MJ, Cusick MV: The difficult colorectal polyp. Surg Clin North Am 2017;97:515527.

9 Corte CJ, Burger DC, Horgan G, Bailey AA, East JE: Postpolypectomy haemorrhage following removal of large polyps using mechanical haemostasis or epinephrine: a meta-analysis. United European Gastroenterol J 2014;2: 123-130.

10 Park CH, Jung YS, Nam E, Eun CS, Park DI, Han DS: Comparison of efficacy of prophylactic endoscopic therapies for postpolypectomy bleeding in the colorectum: a systematic review and network meta-analysis. Am J Gastroenterol 2016;111:1230-1243.

11 Choi YS, Lee JB, Lee EJ, Lee SH, Suh JP, Lee DH, Kim DS, Youk EG: Can endoscopic submucosal dissection technique be an alternative treatment option for a difficult giant $(\geq 30$ $\mathrm{mm}$ ) pedunculated colorectal polyp? Dis Colon Rectum 2013;56:660-666.

12 Mlynarsky L, Zelber-Sagi S, Miller E, Kariv R: Endoscopic resection of large colorectal adenomas: clinical experience of a tertiary referral centre. Colorectal Dis 2018;20:391398.

13 Rutter MD, Nickerson C, Rees CJ, Patnick J, Blanks RG: Risk factors for adverse events related to polypectomy in the English bowel cancer screening programme. Endoscopy 2014;46:90-97.

14 Seo JY, Chun J, Lee C, Hong KS, Im JP, Kim SG, Jung HC, Kim JS: Novel risk stratification for recurrence after endoscopic resection of advanced colorectal adenoma. Gastrointest Endosc 2015;81:655-664.

15 Ferlitsch M, Moss A, Hassan C, Bhandari P, Dumonceau JM, Paspatis G, et al: Colorectal polypectomy and endoscopic mucosal resection (EMR): European society of gastrointestinal endoscopy (ESGE) Clinical Guideline. Endoscopy 2017;49:270-297.

16 Meier B, Caca K, Fischer A, Schmidt A: Endoscopic management of colorectal adenomas. Ann Gastroenterol 2017;30:592-597.

17 Moss A, Nalankilli K: Standardisation of polypectomy technique. Best Pract Res Clin Gastroenterol 2017;31:447-453.

18 Aziz Aadam A, Wani S, Kahi C, Kaltenbach T, Oh Y, Edmundowicz S, et al: Physician assessment and management of complex colon polyps: a multicenter video-based survey study. Am J Gastroenterol 2014;109:1312-1324.

19 Rees CJ, Bevan R, Zimmermann-Fraedrich K, Rutter MD, Rex D, Dekker E, et al: Expert opinions and scientific evidence for colonoscopy key performance indicators. Gut 2016; 65:2045-2060.

20 Murino A, Hassan C, Repici A: The diminutive colon polyp: biopsy, snare, leave alone? Curr Opin Gastroenterol 2016;32:38-43. 
21 Park Y, Jeon TJ, Park JY, Park SJ, Cheon JH, Kim TI, et al: Comparison of clipping with and without epinephrine injection for the prevention of post-polypectomy bleeding in pedunculated colon polyps. J Gastroenterol Hepatol 2015;30:1499-1506.

22 Park CH, Jung YS, Nam E, Eun CS, Park DI, Han DS: Comparison of efficacy of prophylactic endoscopic therapies for postpolypectomy bleeding in the colorectum: a systematic review and network meta-analysis. Am J Gastroenterol 2016;111:1230-1243.

23 Shi K, Shen Z, Zhu G, Meng F, Gu M, Ji F: Systematic review with network meta-analysis: dual therapy for high-risk bleeding peptic ulcers. BMC Gastroenterol 2017;17:55.

24 Brooker JC, Saunders BP, Shah SG, et al: Endoscopic resection of large sessile colonic polyps by specialist and non-specialist endoscopists. Br J Surg 2002;89:1020-1024.

25 Langcroft-Wheaton G, Duku M, Mead R, Basford P, Bhandari P: Risk stratification system for evaluation of complex polyps can predict outcomes of endoscopic mucosal resection. Dis Colon Rectum 2013;56:960-966.

26 Barosa R, Mohammed N, Rembacken B: Risk stratification of colorectal polyps for predicting residual or recurring adenoma using the size/morphology/site/access score. United European Gastroenterol J 2018;6:630-638.

27 Pimentel-Nunes P, Dinis-Ribeiro M, Ponchon T, Repici A, Vieth M, De Ceglie A, et al: Endoscopic submucosal dissection: European society of gastrointestinal endoscopy (ESGE) guideline. Endoscopy 2015;47:829-854.

28 Kandel P, Wallace MB: Colorectal endoscopic mucosal resection (EMR). Best Pract Res Clin Gastroenterol 2017;31:455-471.

29 Wang J, Zhang XH, Ge J, Yang CM, Liu JY, Zhao SL: Endoscopic submucosal dissection vs endoscopic mucosal resection for colorectal tumors: a meta-analysis. World J Gastroenterol 2014;20:8282-8287.

30 Klein A, Bourke MJ: How to perform highquality endoscopic mucosal resection during colonoscopy. Gastroenterology 2017; 152: 466-471.

31 Belderbos TD, Leenders M, Moons LM, Siersema PD: Local recurrence after endo- scopic mucosal resection of nonpedunculated colorectal lesions: systematic review and meta-analysis. Endoscopy 2014;46:388402.

32 Hassan C, Repici A, Sharma P, Correale L, Zullo A, Bretthauer M, et al: Efficacy and safety of endoscopic resection of large colorectal polyps: a systematic review and meta-analysis. Gut 2016;65:806-820.

33 Hirao M, Masuda K, Asanuma T, Naka H, Noda K, Matsuura K, Yamaguchi O, Ueda N: Endoscopic resection of early gastric cancer and other tumors with local injection of hypertonic saline-epinephrine. Gastrointest Endosc 1988:34:264-269.

34 Shinozaki S, Hayashi Y, Lefor AK, Yamamoto $\mathrm{H}$ : What is the best therapeutic strategy for colonoscopy of colorectal neoplasia? Future perspectives from the East. Dig Endosc 2016; 28:289-295.

35 Kandiah K, Subramaniam S, Bhandari P: Polypectomy and advanced endoscopic resection. Frontline Gastroenterol 2017;8:110114.

36 Sakamoto T, Mori G, Yamada M, Kinjo Y, So E, Abe S, et al: Endoscopic submucosal dissection for colorectal neoplasms: a review. World J Gastroenterol 2014;20:16153-16158.

37 Wang J, Zhang XH, Ge J, Yang CM, Liu JY, Zhao SL: Endoscopic submucosal dissection vs endoscopic mucosal resection for colorectal tumors: a meta-analysis. World J Gastroenterol 2014;20:8282-8287.

38 Ma MX, Bourke MJ: Complications of endoscopic polypectomy, endoscopic mucosal resection and endoscopic submucosal dissection in the colon. Best Pract Res Clin Gastroenterol 2016;30:749-767.

39 Burgess NG, Bourke MJ: Endoscopic resection of colorectal lesions: the narrowing divide between East and West. Dig Endosc 2016;28:296-305.

40 Bartel MJ, Brahmbhatt BS, Wallace MB: Management of colorectal T1 carcinoma treated by endoscopic resection from the Western perspective. Dig Endosc 2016;28: 330-341.

41 Benedix F, Köckerling F, Lippert H, Scheidbach H: Laparoscopic resection for en- doscopically unresectable colorectal polyps: analysis of 525 patients. Surg Endosc 2008;22: 2576-2582.

42 Loungnarath R, Mutch MG, Birnbaum EH, Read TE, Fleshman JW: Laparoscopic colectomy using cancer principles is appropriate for colonoscopically unresectable adenomas of the colon. Dis Colon Rectum 2010;53: 1017-1022.

43 Hon SS, Ng SS, Wong TC, Chiu PW, Mak TW, Leung WW, Lee JF: Endoscopic submucosal dissection vs laparoscopic colorectal resection for early colorectal epithelial neoplasia. World J Gastrointest Endosc 2015;7: 1243-1249.

44 Thirumurthi S, Raju GS: How to deal with large colorectal polyps: snare, endoscopic mucosal resection, and endoscopic submucosal dissection; resect or refer? Curr Opin Gastroenterol 2016;32:26-31.

45 Gamaleldin M, Benlice C, Delaney CP, Steele S, Gorgun E: Management of the colorectal polyp referred for resection: a case-matched comparison of advanced endoscopic surgery and laparoscopic colectomy. Surgery 2018; 163:522-527.

46 Heidary B, Phang TP, Raval MJ, Brown CJ: Transanal endoscopic microsurgery: a review. Can J Surg 2014;57:127-138.

47 Brown CJ, Gentles JQ, Phang TP, Karimuddin AA, Raval MJ: Transanal endoscopic microsurgery as day surgery - a single-centre experience with 500 patients. Colorectal Dis 2018;20:O310-O315.

48 Nakajima K, Sharma SK, Lee SW, Milsom JW: Avoiding colorectal resection for polyps: is CELS the best method? Surg Endosc 2016;30: 807-818.

49 Schurr MO, Baur F, Ho CN, Anhoeck G, Kratt T, Gottwald T: Endoluminal full-thickness resection of GI lesions: a new device and technique. Minim Invasive Ther Allied Technol 2011;20:189-192.

50 Schmidt A, Beyna T, Schumacher B, Meining A, Richter-Schrag HJ, Messmann $\mathrm{H}$, et al: Colonoscopic full-thickness resection using an over-the-scope device: a prospective multicentre study in various indications. Gut 2018;67:1280-1289. 